\title{
EL CALOR DE LA TEORÍA
}

\author{
The heat of theory \\ Fernando J. García Selgas* \\ * Universidad Complutense de Madrid \\ fgselgas@cps.ucm.es
}

Palabras

clave

Teoría

Metateoría

Realidad Social

Keywords

Theory

Metatheory

Social reality

\begin{abstract}
Resumen
Este trabajo es una reflexión crítica sobre la apuesta metateórica que Alfonso Pérez Agote hace por lo que él denomina "teoría caliente" (TC). Empiezo analizando qué entiende por TC, cómo argumenta su preferencia por ella frente a la "teoría fría" y cómo la aplica de manera efectiva. Tras recordar que esta tesis resulta un salto en el vacío respecto a planteamientos previos mejor asentados, paso a cuestionar algunos de sus supuestos e implicaciones. Todo ello, más el hecho de que la practica sociológica del propio Alfonso parece incumplir su propuesta, viene a mostrar que la tesis de la TC resulta ser una excusa innecesaria y perjudicial para quien, queriendo ceñirse a la investigación empírica, no puede evitar tomar partido en los debates teóricos y ve la realidad social como una realidad predefinida.
\end{abstract}

\section{Abstract}

This paper is a critical review of Alfonso Perez Agote's metatheorical preference for what he refers as "heated theory" (HT). I start by considering what he understands as HT, how he argues for WT and against "cold theory" and how he deploys WT. After remembering that his choice is a shot in the dark form better, previous options, I come to question some of the suppositions and consequences of this movement. In addition, his own sociological practice does not fit in his choice. I conclude that his preference for HT becomes an unnecessary and detrimental excuse for someone that, willing to stick to empirical research, is unable to avoid taking sides in theoretical debates and sees social reality as a predefined reality.

García Selgas, F.J., 2015, “El calor de la teoría" en Papeles del CEIC, vol. 2015/3, no 134, CEIC (Centro de Estudios sobre la Identidad Colectiva), Universidad del País Vasco, http://dx.doi.org/10.1387/pceic.13294

Recibido: 12/2014; Aceptado: 5/2015

\begin{abstract}
Alfonso Pérez Agote apuesta por lo que denomina "la teoría caliente" (TC, a partir de ahora) y mi propósito es reflexionar críticamente sobre ello. No me concentraré en los conceptos y teorías que viene desplegando Alfonso en la TC, sino en la apuesta misma, que es una cuestión metateórica. Creo que, en última instancia, la tesis de la TC es una excusa innecesaria, injusta con las labores teoréticas y con implicaciones perjudiciales para alguien que, como Alfonso, quiere
\end{abstract}


concentrar su trabajo en la investigación empírica sin tener que verse involucrado en los debates más teoréticos, pero no evita tomar partido en ellos.

\section{1. ¿QUÉ SE QUIERE DECIR Y HACER CON LA "TEORÍA CALIENTE"?}

\subsection{La tesis de la teoría caliente}

En una reciente y, como siempre, generosa conversación con Alfonso, me decía que su apuesta por la TC había surgido por analogía con una concepción "física" del calor como efecto del rozamiento, de modo que al rozarse con la realidad social la teoría se calentaría, sería TC, y que ese es el tipo de teoría que le gusta. Dado que las concepciones que dominan en física hablan de contacto más que de rozamiento ${ }^{1}$ no descarto que, en el fondo, su inspiración provenga de una concepción más humana que física del calor, esto es, del calor humano, el calor que nos da el roce con los otros. Volveré sobre esto al final.

Si no me equivoco la primera vez que Alfonso apuesta por la TC como necesidad imperante en la sociología contemporánea es en 1995, en un trabajo sobre el multiculturalismo. Alli define la TC como aquella teoría que está "en permanente contacto e incluso lucha con la realidad social cambiante que nos rodea" (1995: 81), la contrapone a las teorías frías (TF), "cuyas referencias sean no tanto la realidad más directa cuanto otras teoría" (Ibid.), y la defiende porque "nuestros modelos, conceptos y teorías están destinados a ser confrontados, mediante el análisis, con la realidad social" (Ibid.).

Era una propuesta todavía incipiente, que se desarrollaría en un escrito posterior que reiteraba la tesis de la TC al afirmar (1999: 57) que la TC "consiste en enfrentar directamente a la teoría con la realidad inmediata, en lugar de hacerlo con otras teorías, lo que constituiría un ejercicio de teoría fría".

\subsection{El argumento que la sustenta}

Esta diferenciación entre TC y TF, así como la preferencia absoluta por la

\footnotetext{
${ }^{1}$ En la física contemporánea (en termodinámica) el calor se define como la transferencia de energía (no solo térmica) que se produce por conducción (contacto), radiación (electromagnética) o convención (movimiento de fluidos). Antes, hasta el siglo XIX, se explicaba el calor o el cambio de temperatura por efecto de un fluido invisible llamado calórico, que se producía cuando algo se quemaba y podía pasar de un cuerpo a otro.
} 
primera, se sustentan sobre un razonamiento cuyos pasos son:

$1^{\circ}$ Empieza proclamando la certeza de que "al concepto de perro, por mucho que nos empeñemos, le dediquemos tiempo y lo operacionalicemos, no podemos hacerle ladrar (Spinoza, en Althusser, 1969). Nuestros conceptos, teorías, ideas, representaciones, imágenes, etc., no son la realidad, ni siquiera la tocan" (1999: 57). Para asegurar esta última afirmación que, mediante un deslizamiento muy discutible (del "no son la realidad" al "ni siquiera la tocan"), establece una separación radical entre teoría y realidad, convoca al problema kantiano de las condiciones de representación, a la incapacidad de la fenomenología para llevar la representación hasta su objeto y a la poca seguridad epistemológica que nos ofrecerían la praxis o la tecnología (frente a lo que había sostenido él mismo en 1989).

$2^{\circ}$ En esa situación, dice, tendríamos cuatro alternativas: a) quedarnos en la separación radical entre teoría y realidad, como hizo Althusser acarreando curiosamente "importantes consecuencias prácticas"; b) dejar la actividad científica; c) dedicarnos a la epistemología y la metodología, intentando "establecer las normas que nos hagan tocar al objeto", lo que le parece casi peor; y d) "hacer-como-si, comenzar nuestra investigación diciéndonos a nosotros mismos 'hagamos como si pudiéramos conocer'" (1999: 57).

Las tres primeras alternativas se toman en serio lo sostenido en el primer paso e intentan afrontarlo de una manera $u$ otra, mientras la última, que él adopta y nos lleva a la TC, lo señala pero no quiere asumirlo. Es por ello la denegación de lo sostenido en el primer paso. Pero es también expresión del deseo del investigador empírico que, situado entre la teoría y la realidad, se sueña capaz de hacer lo que ni Kant, ni la fenomenología, ni la praxis, ni la tecnología habían logrado.

$3^{\circ}$ Quizá sea esa situación lo que conduce la contradictoria literalidad del último paso: "Si el objeto de la teoría, dice Alfonso (Ibid.: 57), no es la teoría, sino la realidad -por más que esta sea inalcanzable [como se habría mostrado en el primer paso, añado yo]-, entonces debemos confrontar nuestra teoría con la realidad, con aquello que definimos como tal".

Pero ¿sobre qué base definimos la realidad? ¿No será sobre la base de nuestros conceptos y teorías? Si es así, como él mismo hace al desplegar la TC y ahora mostraré, entonces resulta que o bien no es tan insuperable la 
distancia entre teoría y realidad o si lo es no se logra salir del círculo que marca la teoría, el círculo interpretativo de las representaciones.

\subsection{La práctica de la TC}

Su manera concreta de hacer TC consiste en este caso, según sus propias palabras, en "establecer ciertos marcos de reflexión sobre la significación" de la entrada de España en la Unión Europea: "comenzar una reflexión, dando pistas sobre algunos de los ámbitos teóricos en los que ésta debe situarse" (1999: 58). De hecho, el trabajo se dedica a presentar una malla teórico-conceptual que se quiere lanzar sobre lo que pensamos que está pasando, sobre la "realidad" tal y como la definimos inicialmente. Lo cual viene a ser un ejercicio de re-conceptualización de la realidad.

En este texto la "realidad" aparece descrita y definida sobre la base de una serie de generalizaciones (de generalizaciones empíricas a teorizaciones de rango muy bajo) amparadas en datos de base más o menos estadística, como al dibujar la crisis del Estado de Bienestar, siguiendo a Cachón (Ibid.: 60), en análisis históricos, como al describir el proceso de centralización de la política europea (Ibid.: 70), o incluso en opciones un tanto ideológicas, como al afirmar (Ibid.: 58) que la nación siempre viene detrás del Estado.

Por su parte, la malla teórica que se quiere rozar con esa "realidad" tan conceptualmente cargada se teje con hilos de distinto calado teorético:

- Teorizaciones de lo más abstracto y general, incluso frías, como afirmar taxativamente "cuanto mayor es el agregado [social] más abstracto es" (Ibid.: 65); "el momento político es el momento de la constitución de la sociedad total: la política genera la totalidad, es la constitución de la totalidad" o "la comunidad es el límite subjetivo del poder" (Ibid.: 59).

- Teorizaciones de rango medio, que se suponen referidas a un espacio histórico más o menos concreto, como "la globalización es anómica" (Ibid.: 66) o "la crisis hace referencia al Estado como condensación total dominante de la realidad social" (Ibid.: 61).

- Opciones tomadas respecto a debates teoréticos (no sé si fríos o templados) como el que se produce en el seno de la tradición estructuralista en torno al lugar que ocupa la tensión centroperiferia en los procesos de diferenciación funcional y conformación reticular (Ibid.: 68) o el más clásico sobre "la argamasa moral (...) de una sociedad" (Ibid.: 65). 
De este modo la TC termina consistiendo en cubrir hábilmente una realidad descrita y observada desde un determinado marco-conceptual con una malla teorética de mayor alcance o penetración ${ }^{2}$. Es un ejercicio de re-conceptualización o reinterpretación que o nos mantiene alejados de la realidad y sin rozarnos con ella, encerrados en "fríos" marcos conceptuales-teóricos, o desdibuja la separación radical entre la teoría y su objeto, negando así el primer paso del razonamiento.

Lo único que se logra con la TC es soslayar el problema epistemológico, desechar el desarrollo autónomo de la teoría y asumir supuestos e implicaciones problemáticos. Antes de revisar unos y otras conviene recordar de dónde proviene esta especie de salto en el vacío, lo cual me permite además ser algo más justo con la trayectoria de nuestro autor.

\section{El salto al Vacío de la tesis de la TC}

Alfonso saltó sin ninguna red de protección de una serie de reflexiones coherentes con el estado de la cuestión en la segunda mitad de los 80 a esta poco elaborada y discutible tesis de la TC. Fue un salto atrás, gestado quizá en la amarga y escolástica resaca de las viejas oposiciones.

En un trabajo que recogía su memoria de cátedra (1989) intentaba superar los dilemas originarios de la Sociología, básicamente el que se da entre objetivismos (estructuralismo, marxismo) y subjetivismos (fenomenología, individualismo, etc.) y el que se produce entre consenso y conflicto. Pero, en lugar de subirse al carro de los intentos más prometedores (Bourdieu, Giddens), se dejó seducir por el equilibrio ecléctico de Berger y Luckman, que terminaría siendo una perniciosa influencia para la tesis de la TC.

En ese libro hay una interesante reflexión sobre la constitución inicial de la realidad social como totalización política y espacio empírico entre el individuo y el Estado-nación, que se habría producido durante el siglo XIX y la primera mitad del XX (1989: 15-37), y sobre cómo, a partir de los años 60, esa realidad social estallaba en "una multiplicidad de microfenómenos generalmente conflictivos" y se desvanecía por "la privatización de la vida y la autonomización de la política" (Ibid.: 57). De este modo, para los sociólogos, la realidad social habría pasado de ser "una evidente realidad

\footnotetext{
${ }^{2}$ Encontramos la misma mixtura ecléctica de generalizaciones, enunciados teóricos y observaciones concretas en su primera aplicación de la TC, centrada en ajustar y puntualizar la teoría de la "solidaridad nuclear" (Geertz, Alexander) como malla teórica con la que cubrir analíticamente el multiculturalismo (Pérez-Agote, 1995: 93-7).
} 
empírica" a convertirse "hoy en día en "una realidad conceptual" (Ibid.: 57), como en el resto de las ciencias (Ibid.: 85-86).

Desde ahí aludía también al famoso perro de Spinoza, formulaba el problema de la separación teoría-realidad de un modo similar al que hemos visto y proponía que las ciencias pueden obviarla y montarse sobre ella ${ }^{3}$. Pero no daba el salto al vacío de la TC, sino que desplazaba dicho problema a la Epistemología (Ibid.: 86) y señalaba la existencia de una serie de relaciones prácticas (puentes) entre teoría y realidad (Ibid.: 83):

1. Reducir el problema a la cuestión práctica de "valorar un concepto, un modelo, una teoría, como superior a otra" (Ibid.: 85, nota 59).

2. Tomar los indicadores sociales como operativización de los conceptos teóricos, que mediarían así entre teoría y realidad empírica (Ibid.: 114)

3. Evitar "predicar una única forma de conocer la realidad" (Ibid.: 86).

4. Tener en cuenta que la ubicación de la Sociología "en el interior de la realidad objeto de estudio" y su consiguiente reflexividad (Ibid.: 83) permiten que concepto y realidad se vinculen en la legitimación del ordenamiento cultural de la realidad (Ibid.: 88-89; Ibid.: 148) y la contribución que a él hace la Sociología (Ibid.: 99).

El caso es que todos estos matices y reflexiones que le habrían permitido practicar esa investigación empírica con ribetes de reflexión teórica que caracterizan su trabajo quedaron marginados por la sonora, pero problemática, tesis de la TC. Así que volvemos a ella para cuestionar sus supuestos.

\section{ReVISIÓN DE LOS SUPUESTOS DE LA TC}

\subsection{Supone una cierta confusion entre historia de la teoría, debates teóricos y metateoría}

El tercer paso de la argumentación, el conclusivo, comienza diciendo (1999: 57): "el objeto de la teoría no es la teoría" entendiendo por esta segunda el

\footnotetext{
3 "El concepto no es la realidad concebida. La realidad sociológica es una realidad conceptual, es decir, es una representación conceptual de una zona conceptualmente delimitada de la realidad. Pero ([ello]...) no debe llevarnos a postular que el objeto de la sociología sea la sociología porque toda ciencia está montada sobre el supuesto de que se da alguna relación entre el concepto y su objeto. Cuál sea esta relación, es decir, el desentrañamiento de este supuesto pertenece, en nuestra división del trabajo, a la filosofía y, gracias a este desplazamiento, las ciencias pueden avanzar montadas en el supuesto e 'ignorando' su consistencia" (Pérez-Agote, 1989: 83).
} 
trabajo de otros teóricos. Con ello propone excluir del trabajo teorético tanto los debates teóricos, cuanto los análisis históricos de la producción teórica y las reflexiones metateóricas. Aunque, como hemos visto, su propia aplicación de la TC incluye la participación en esos debates, la referencia a los clásicos y el apunte de problemas metateóricos. Y al hacerlo subrepticiamente lo mezcla todo indiscriminadamente, simplificando y oscureciendo el trabajo teorético.

No se puede justificar esa incongruencia y la confusión correspondiente por el constructivismo reflexivo que se deriva de su idea de que la "auténtica actualidad" de los clásicos (1989: 177) estriba en su asimilación reflexiva por la sociedad (Ibid.: 176) que los convertiria en imprescindibles para establecer el "pasado presente" (Ibid.: 174), dada la pre-ordenación sociológica de la realidad social. Pues nada de ello impide diferenciar entre esos tres ámbitos de trabajo de la teoría ni niega la relevancia de esta para el conocimiento de la realidad empírica (se roce o no con ella).

\subsection{Supone una separación radical entre teoría y realidad}

El supuesto inicial de su argumentación afirma que "Nuestros conceptos, teorías, ideas, representaciones, imágenes, etc., no son la realidad, ni siquiera la tocan." (1999: 57) ${ }^{4}$. Tal separación radical entre teoría-concepto y realidad-objeto, que impulsa a la tesis de la TC, no le ha impedido, sin embargo, una pirueta dialéctica al postular que "saltemos sobre ese supuesto", que hagamos "como si" no estuviera, que "debemos confrontar nuestra teoría con la realidad, con aquello que definimos como tal" (ibid.).

La única forma de que esa pirueta no sea una contradicción o un movimiento irreal consiste en pensar que si el concepto de perro no ladra entonces mi definición de lo social no constituye realidad y, por lo tanto, 0 permanecemos alejados de la realidad, caminamos científicamente a su lado y no nos rozamos con ella, o tenemos que rechazar la supuesta separación radical entre la teoría y su objeto y, con ella, el motor de la TC.

Si al concepto de perro no le podemos hacer ladrar es porque ya ladra, aunque menos que el perro. Menciona "serpiente" a alguien que tenga una fobia y le verás dar un respingo. Si este sonido (guau) es un ladrido producido por un perro es porque en nuestra interacción con este tipo de

\footnotetext{
${ }^{4}$ Lo que conlleva un deslizamiento muy discutible del "no son la realidad" al "ni siquiera la tocan", que parece gestado en los debates en torno al estructuralismo marxista de Althusser y Poulantzas.
} 
animales nos resulta práctico y justificado diferenciar el sonido que hace y denominarlo así, de manera diferente a otras lenguas, por cierto.

Contra la separación de la palabra y su objeto de referencia (la palabra "perro" del animal que ladra) Wittgenstein (1988: §120) dice: "La moneda y la vaca que se puede comprar con ella. (Pero por otra parte: la moneda y su utilidad)". Es la "utilidad" del concepto de perro, de los conceptos sociológicos, su modo científico de conectarnos con las cosas que pasan lo que constituye nuestro punto de partida, incluso de la observación, no una distancia que queda anulada por su uso.

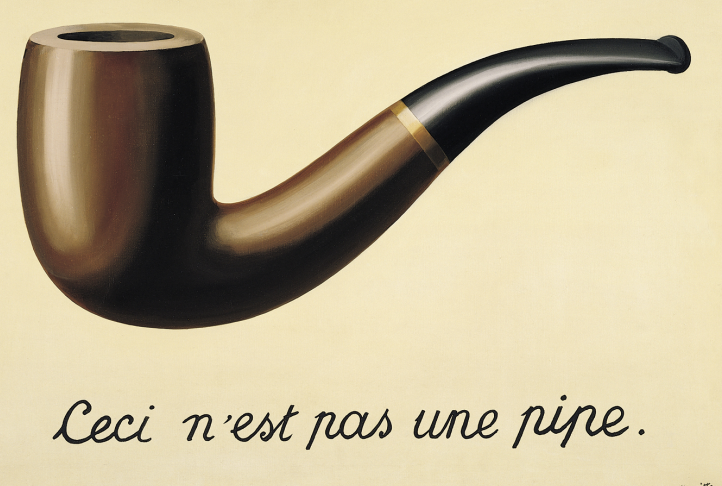

No podemos fumar en esta pipa y por ello "no es una pipa", pero lo mismo que nos permite llamarlo pipa es lo que hace que esta-cosa-en-la-quefumo sea una pipa: la una depende de la otra o, mejor, del lugar que ambas tienen en nuestras prácticas.

\subsection{Supone la separación entre teoría y práctica}

Como parte del supuesto anterior o como supuesto adicional, la TC conlleva admitir que teoría y práctica son realidades radicalmente distintas o que pueden plantearse así. Es cierto que el propio Alfonso ve en el teoreticismo althusseriano "importantes consecuencias prácticas" (1999: 57) y que sitúa a la Sociología en el interior de la Sociedad (1989: 83). Pero la mera definición de la TF supone que es posible un ejercicio de la teoría totalmente alejado de la práctica.

Pero, tras las propuestas constructivistas y postestructuralistas (y sus excesos), no resulta posible pensar por separado el trabajo teorético, por muy "frío" que sea, y la práctica social, por más automática que parezca. La reflexividad social y la performatividad de la Sociología se conjugan para 
hacer que por muy enfrascada que esté una elaboración teórica en su propia problemática, no dejará de contribuir a definir qué es pensable, qué es posible y cómo ver la realidad social. Hablaremos así de una práctica teórica, del hacer de la teoría y de que, si es su imbricación con la realidad social lo que la calienta, entonces no llegaría nunca a enfriarse del todo.

\section{DivergenCIAS FRENTE A LA IMPLICACIONES DE LA TESIS DE LA TC}

Inmediatamente conectadas con estos supuestos, especialmente con el último, hay una serie de implicaciones que también muestran limitaciones de la tesis de la TC.

\subsection{Mejor no quemarse con la voluntad legisladora}

$\mathrm{Si}$, como Alfonso, se asume la separación entre teoría y práctica, se piensa que la sociedad viene fundada por el hecho político y se sitúa uno en la tradición de la Sociología como ciencia moral, es muy probable que nos dejemos arrastrar por la tendencia legisladora de la Sociología, por su voluntad de marcar el camino de la práctica social. Pero esta implicación conlleva dotar a la Sociología de unos poderes que no están justificados, y menos en una sociedad democrática, y pensar que el resto de los actores sociales, incluyendo gestores, políticos profesionales, movimientos sociales, etc. necesitan de nuestra guía. Como si no fuera suficiente con el trabajo profesional de una Sociología que analiza e interpreta el acontecer, siendo conscientes de que ello es ya un movimiento en medio de las prácticas sociales.

Reconocer el carácter práctico de la investigación y la teorización, su naturaleza templada, nos ayuda a evitar no solo esa tentación legisladora, cuando no partisana, sino también el distanciamiento positivista y el intelectualismo ilustrado.

\subsection{Ver la tension centro/periferia en los trabajos teoréticos}

Si llevamos el interés de Alfonso por la tensión centro-periferia de los procesos de diferenciación (1999:68) al trabajo teórico mismo, podemos contrarrestar su concepción abstracta e inmaterial de la teoría.

Se habla de la teoría como si el trabajo teorético se realizara fuera de las coordenadas sociohistóricas, como si ese trabajo no estuviera atravesado por desigualdades de poder. La teorización sociológica se produce o, mejor dicho, se regula desde nodos concretos de las redes científico-académicas, 
que no casualmente se ubican en los centros hegemónicos (Paris, Viena, Nueva York, etc.). Para contrarrestar tal dominación y empujados, en buena medida, por la sensibilidad postcolonial llevamos algo más de dos décadas reivindicando las teorías del sur (Connell, 2007) o incluso las epistemologías y metodologías del sur (Santos, 2014).

Aquí está otra vez lo curioso. Alfonso, que ha sido sensible a la crítica al colonialismo, principalmente a la proveniente del África francófona, no ha apreciado que una lucha similar y paralela se producía en el ámbito teorético. No ha visto que las periferias, incluyendo las periferias noroccidentales como nuestra academia hispana, si no quieren ser meros voceros de los centros hegemónicos, necesitan desarrollar teorizaciones divergentes. Ello implica un trabajo en el interior de la teoría, que es simultáneamente una acción sociopolítica, pero que no puede ser un movimiento aislacionista o purista, sino que, como Malinche -la india amante y traductora de Cortés- se sabe mestizo y tortuoso.

\subsection{Del calor de la teoría como oído y sensibilidad}

La teoría social se calienta, según Alfonso, no por mantener la atención sobre la realidad (que supone inaccesible) sino porque se roza con ella. La calidez de una teoría vendría dada por su capacidad de enredarse (¿o comprometerse?) con la realidad social, pero ello no le asegura ni la eficacia práctica, ni la clarividencia cognitiva, ni la consistencia teórica.

Si quisiéramos tildar de cálidos a los trabajos teóricos que nos parecen más constructivos, yo señalaría otras fuentes de calor: el oído para escucha el rumor del fluir social, de los flujos y tendencias del acontecer social; la sensibilidad para reconocer sentidos, valores y prácticas emergentes o, al menos, divergentes de las institucionalizadas o ya conceptualizadas; y el compromiso con la profesionalidad, con el trabajo bien hecho, con el rigor.

\section{UNA PRÁCTICA MÁS TEÓRICA Y TEMPLADA DE LO QUE PREDICA}

Por último voy a intentar mostrar que la práctica científica de Alfonso contraviene su tesis de la TC. Para ello necesito que recordemos dos cosas:

1. La raíz etimológica de teoría remite a visión, bien porque provenga de "theuros", espectador (del oráculo) o de "Theus (=Zeus) orao", visión divina o con-templación (= visión desde el templo). Nos remite a una visión atenta y superior. 
2. Al comienzo de esta reflexión sugerí que, al establecer la identificación entre calor y rozamiento, Alfonso quizá estuviera pensando en una concepción más humana que física del calor, esto es, pensando en el calor humano, el calor que nos da el roce con los otros.

Añadamos a ello la experiencia que hemos tenido muchos al trabajar con Alfonso ${ }^{5}$. Su modo de concebir y vivir la Sociología, no como un trabajo con horario sino como una forma de estar en el mundo y de ver el mundo, hace que sea en el intercambio informal y no en el aula o en una conferencia donde más nos enseña a percibir un hecho, relación o proceso social. Nos hace ver y él mismo es "una forma de ver el mundo", una especie de teórico andante que, cuando casi sin darte cuenta consigue insuflarte una visión, te hace ver. Genera visión y, en este sentido, hace teoría de la buena, ni fría ni caliente, templada, porque ello nada tienen que ver con el rozamiento con los problemas sociales, sino con el desarrollo de una sensibilidad (un "oído" dice él) capaz de percibir, apreciar y expresar lo más importante del acontecer social.

Guardo o, más bien, atesoro, una de esas experiencias: aquella en que Alfonso me hizo ver con claridad y enorme hondura personal y humana la base corporal-relacional del sentido y de la identidad, algo sobre lo que llevaba y llevo muchos años trabajando e investigando. Puso ante mis ojos y ante mi corazón lo que mis reflexiones no terminaban de vislumbrar. Fue en una comida en la Facultad. No recuerdo de qué estábamos hablando. De repente me dijo que él, que no pudo conocer a su padre con vida, cuando sus hermanos querían contarle cosas de su padre les cortaba rápidamente y les mandaba callar, porque nadie podría jamás decirle lo más importante, lo que uno siente cuando su padre le abraza o le acaricia.

¿Querías teoría (visión) de la encarnación como base del sentido, Fernando? Pues ahí la tienes. Su calidez no brota del roce con la realidad social, ni de la confrontación con otras visiones (teorías), sino de vivir y mirar sociológicamente, de ser capaz de visibilizar las claves de la socialidad que nos constituye. Lo cual no excluye la relevancia que tienen para el desarrollo de la teoría esas confrontaciones o las reflexiones metateóricas.

\footnotetext{
${ }^{5}$ A mi se me hizo clara hace unos años, tras una larga conversación con Iñaki Martínez de Albéniz.
} 


\section{Bibliografía}

Althusser, L., Balibar, E., 1969, Para leer El Capital, Siglo XXI, México.

Connell, R. 2007, Southern Theory, Polity Press, Cambridge.

Pérez Agote, A., 1989, La sociedad y lo social, UPV, Bilbao.

Pérez Agote, A., 1995, "Reflexión sobre el multiculturalismo que nos viene", en E. Lamo (Ed.), Cultura, Estados, Ciudadanos, Alianza, Madrid, pp. 81-102.

Pérez Agote, A., 1999, "Globalización, crisis del Estado y anomía. La teoría social visita Europa", en R. Ramos y F. García Selgas (Eds.), Globalización, riesgo, reflexividad. Temas de la teoría social contemporánea, CIS, Madrid, pp. 57-72.

Santos, B. S., Meneses, M. P. (Eds.), 2014, Epistemologías del Sur, Akal, Madrid.

Wittgenstein, L.,1988, Investigaciones Filosóficas, Crítica, Barcelona. 